\title{
Multisociety Conference on Materials Science Held in Cancún in August 2004
}

The Academia Mexicana de Ciencia de Materiales, also known as Mexican Materials Research Society (MexicanMRS), joined the Asociación Mexicana de Microscopía, the Iztapalapa Science SolGel and Technology Society, the Academia Mexicana de Química Inorgánica, and the National Association of Corrosion Engineers (NACE) International to produce the XIII International Materials Research Congress 2004 (IMRC-2004), VII National Congress of the Mexican Microscopy Association, I Iztapalapa SolGel Science and Technology Congress, IX Ibero-American Congress of Inorganic Chemistry, and III National Association of Corrosion Engineers (NACE) International.

The multisociety meeting was held August 22-26, 2004, in Cancún, México. The meeting provided an interactive forum for discussing advances in corrosion, electron microscopy, synthesis, characterization, properties and processing, applications, basic research trends, and education in the area of materials science. The president of the Mexican-MRS, Ventura Rodríguez Lugo, served as the general chair. René Asomoza Palacio, director of the National Researchers System of the National Council of Science and Technology (CONACYT), opened the event, emphasizing the relevance and importance of the congress to the development of new knowledge and future technology for Mexico.

The conference consisted of 20 symposia attended by over 830 delegates from several countries. There were 1004 presentations delivered as invited talks, oral presentations, and posters. The conference awarded 120 scholarships. The event included 10 plenary lectures, an exhibit, and seven tutorials.

An Industry-Academic Panel was held in order to build a productive exchange and cooperation between universities and industry. The goal was to establish a comprehensive industrial-academic collaboration alliance in order to create new industries through research and development and to develop innovative products

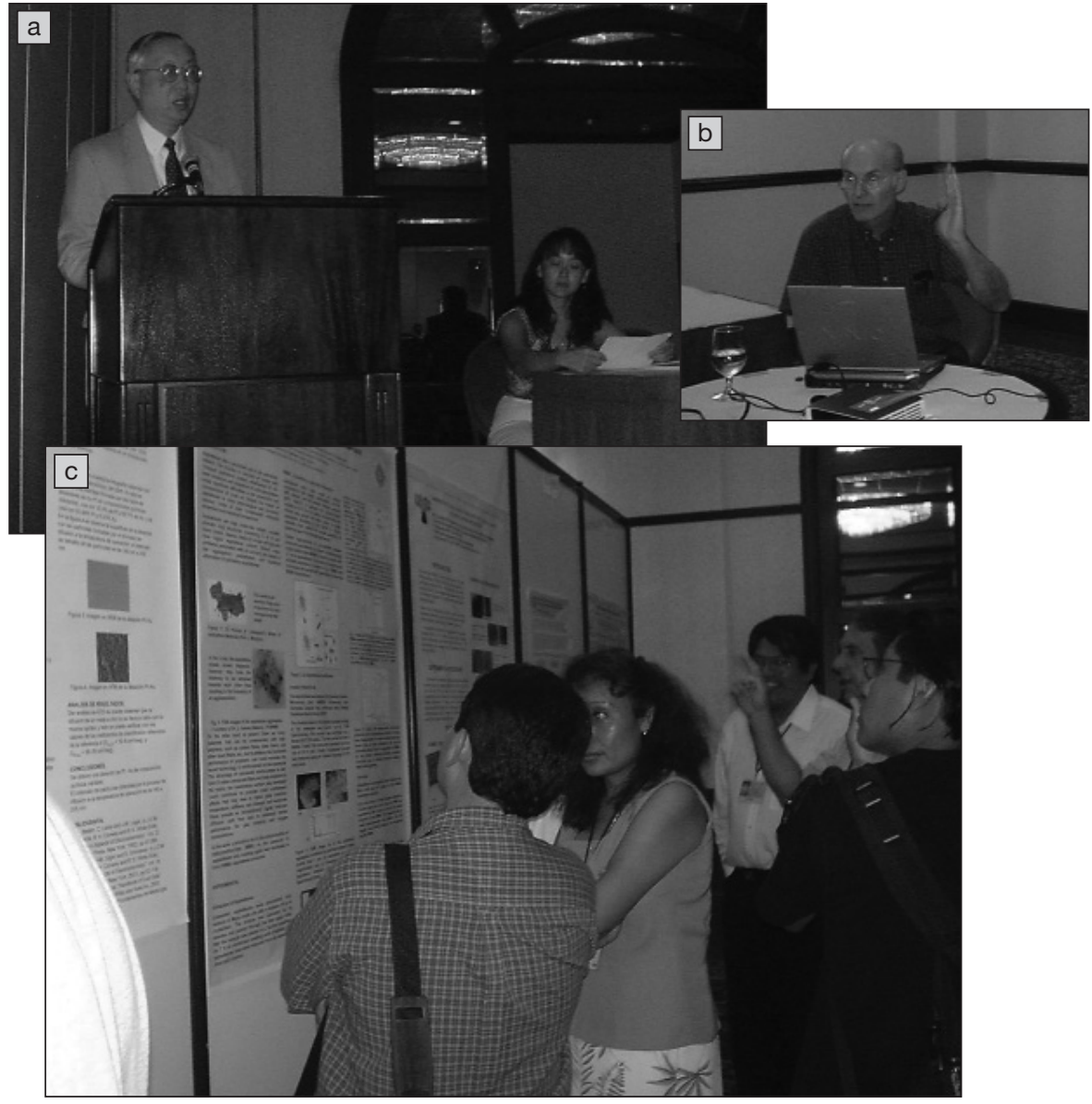

(a) R.P.H. Chang (Northwestern University), the general secretary of the International Union of Materials Research Societies, addressed the XIII International Materials Research Congress in the opening session. (b) H.W. Siesler (University of Duisburg-Essen, Germany) provided a tutorial on "Basic Principles, Instrumentation, and Applications of Vibrational Spectroscopy in Materials Science." (c) Poster sessions were held at the multisociety conference on materials science.

and ideas for global marketing. Representatives came from Grupo Jaguar, RG Industrial, the Universidad Nacional Autónoma de México, Centro de Tecnología Cemento y Concreto, DESC Group, and Tulane University in New Orleans.

In order to promote active connections and the advancement of women in science, a networking luncheon was organized by IMRC-2004, with the aim of pro- moting equity and full participation of women scientists in Mexico at all levels. Mildred S. Dresselhaus (Massachusetts Institute of Technology) and Merrilea J. Mayo (the National Academies) were the guest speakers. The luncheon was open to all attendees interested in supporting women's advancement in science.

VENTURA RODRÍGUEZ LUGO President, Mexican-MRS

\section{WORKSHOP}

Immediately following the 2005 MRS Spring Meeting in San Francisco, The Physics and Chemistry of Switching in Condensed Matter workshop will explore fundamental mechanisms of switching in a variety of materials. Switching phenomena will include phasetransitions, as well as other sudden transitions in conductivity, magnetism and optical density.

\section{The Physics and Chemistry of Switching in Condensed Matter April 1-2, 2005 - San Francisco, California}

Technical Committee Chair-Dr. Arthur Edwards of AFRLNS, Albuquerque.

For the most up-to-date information on this workshop and other meeting activities from the Materials Research Society, visit www.mrs.org/meetings/ 